\title{
The Feminine and the Pubertarian: The Pubertarian Novelty According to Freud and Lacan
}

\author{
Olivier Ouvry \\ Laboratory UTRPP EA 4403, University Sorbonne-Paris-Nord, Paris, France
}

\author{
Email address: \\ 1 @oouvry.fr
}

\section{To cite this article:}

Olivier Ouvry. The Feminine and the Pubertarian: The Pubertarian Novelty According to Freud and Lacan. American Journal of Psychiatry and Neuroscience. Vol. 9, No. 3, 2021, pp. 90-97. doi: 10.11648/j.ajpn.20210903.13

Received: December 5, 2020; Accepted: December 14, 2020; Published: August 7, 2021

\begin{abstract}
Countless authors have attempted to theorize the passage from the infantile to the juvenile. This passage is not without consequence, as shown by the changes in the semiological and nosological fields, corroborated by the infantile amnesia subsequent to this phase. We propose to approach this question through a re-reading of Freud's texts. We shall highlight how Freud's attempt at qualifying infantile sexuality led him to define more and more clearly what distinguishes it from juvenile sexuality; nevertheless he failed to define the threshold that separates them. Thus, on the one hand he reached the threshold of the impossible whilst on the other, and despite himself, he indicated viable clues to its potential theorization. To Freud, this impossibility constituted an impasse at the time. Contributions from linguistics and structuralism allowed for a theoretical opening towards it. To Lacan, it characterizes the Real, the Other jouissance (specific to woman) and the Other's lack signifier S $(\mathbb{A})$. We shall conclude that the pubertarian novelty is the effect - brought by the Real - of the body's physiological change when it becomes pubertarian. Our hypothesis is in accordance with what Freud had identified as proper to puberty, namely "the displacement of erogenous zones from the clitoris to the vagina". We may call this effect the advent of the Feminine, vector of the Other sex, which cannot be inscribed in the infantile, phallocentric world. In other words, it is a bodily experience that has no equivalent in the Symbolic realm. Lacan translated this experience into "there is no signifier to woman's sex". This Feminine (the capital F indicates its non-inscription in the Symbolic realm) will, during the time of adolescence, find a formalization - not via a signifier which is defaulted but via an object present in reality (which can be the Other sex's other as much as any addictive, source of jouissance object).
\end{abstract}

Keywords: Pubertarian Novelty, Adolescence, Feminine, Freud, Lacan

\section{Introduction}

We will begin our discussion with an observation: that, to our surprise, most psychoanalytic theoreticians have an astonishing lack of knowledge regarding the pubertarian phenomenon.

Countless analytic texts we have read do not highlight this phase. They describe the infantile period and then immediately move to the juvenile or adult phase without outlining what might have constituted the interval between states, thence failing to validate what they have already accepted as a difference ${ }^{1}$. As for the authors who take a

1 Confers, among other things: Stortelder F. (2010), Adolescence and the Reorganization of Infant Development: A Neuro-Psychoanalytic Model, September 2010, DOI: 10.1521/jaap.2010.38.3.503 - Source: PubMed; Jeammet Ph. (2005), Adolescent crisis in International Dictionary of Psychoanalysis, Alain deeper interest in adolescence, the subject is often centered on the revival of the mirror stage or the Oedipus complex the consequence being to annihilate any possible difference!

Rather than consider this ignorance a result of the authors' theoretical reference, we must consider it within a larger historical context. Hence, we introduce an epistemological reading wherein the theoretical objects, or concepts - analytic or otherwise - only gain consistency at the precise moment in the history of their theoretical body. The preceding advances are the consequence of intuition, while the subsequent ones are a result of what was then considered acquired from the theoretical body already established.

de Mijolla, Thomson Gale, 2005; Adolescent Development and the Biology of Puberty: Summary of a Workshop on New Research.

National research council, institute of medicine. Copyright 1999 by the National Academy of Sciences. 
By necessity, the pubertarian object obeys these rules. The slow, laborious advent of this notion illustrates this. Such an advent resembles the unveiling of an incandescent object, blinding at first to those who approach it, and only allowing itself, very progressively, to be approached by a reflection, in a more serene and lucid manner.

Is a theorization of the pubertarian finally possible? The present article will try to answer this question.

We shall build our case based on this perspective. First, by showing how Sigmund Freud indirectly approached this object that was impossible a century ago. Secondly, we will try, based on the above cited text by Serge André, to set the reference points of a sexual theory of the adult subject, namely that of Jacques Lacan. Finally, we will fill the gap between infantile sexual theories - including Sigmund Freud's premonitory intuitions - and the adult subject's sexual theory. We will attempt to do so based on adolescence theoreticians, particularly Phillipe Gutton. We shall here find the establishment of the Feminine as the pubertarian phase's specificity.

\section{Sigmund Freud's Reading}

As of 1905, in the Three Essays on the Theory of Sexuality, Freud took an interest in the particularities of the prepubertarian child's sexual evolution until the advent of puberty. The unique libido's thesis, never abandoned by Freud, is presented here, and will be at the origin of psychoanalysis pioneers' quarrels. We quote Freud: "the male and female dispositions are easily recognizable even in infantile life (...). But, the autoerotic activity of the erogenous zones is the same in both sexes, and it is this agreement that removes the possibility of a sex differentiation in childhood as it appears after puberty. In respect to the autoerotic and masturbatic sexual manifestations, it may be asserted that the sexuality of the little girl has entirely a male character. Indeed, if one could give a more definite content to the terms "masculine and feminine," one might advance the opinion that the libido is regularly and lawfully of a masculine nature, whether in the man or in the woman; and if we consider its object, this may be either the man or the woman" ([3], p. 181).

Hence, puberty is implicitly charged with instituting a differentiation element between masculine and feminine sexuality. And, "if little girls' sexuality has an entirely masculine character" as Freud insists, isn't it possible to defend the hypothesis that the pubertarian movement is characterized by the introduction of what lacks in the infantile sexuality, that is, the Feminine?

We shall see how the different texts from La vie sexuelle ${ }^{2}$ slowly explore this question. We quote Freud: "The startingpoint and the final aim of the process which I have described are clearly visible. The intermediate steps are still in many

2 Freud, S. La vie sexuelle, Paris, PUF, 1977 [10]. This book contains a selection of Freud's articles found in different volumes of The Complete Psychological Works of Sigmund Freud, Standard Edition, W.W. Norton \& Company. ways obscure to us. We shall have to leave more than one of them as an unsolved riddle" ([3], p. 208). The pubertarian phase's enigmatic character subsists throughout all of Freud's works, which is not surprising. The epistemological perspective we have previously exposed helped us understand how, in the era when the pubertarian object epistemologically emerged, a deeper conceptualization was impossible to attain.

If, however, Freud was unable to approach the pubertarian object directly, his questions related to boys' and girls' sexual development seem to us to overlap certain points that offer an indirect approach to the theorization of adolescence. Using this observation, we propose that the Feminine - as a pubertarian time specificity - had already been addressed by Sigmund Freud.

Two points sustain our hypothesis: on the one hand, the observation of a progressive reduction of what marks the difference between what comes before and after puberty which we understand as something specific and more and more pronounced than what is at stake at such moment. On the other hand, Freud always sustained the centering of the pubertarian transformation on the little girl's sexual development - while the boy's is described as a continuity of the previous phase, hence deprived of any particularities during adolescence.

The first point thus concerns the difference between puberty before and after. Regarding the second half of childhood (from the age of eight until puberty) Freud indicates that "During these years the genital zones already behave in much the same way as in maturity; they become the seat of sensations of excitation and of preparatory changes whenever any pleasure is felt from the satisfaction of other erotogenic zones, though this result is still without a purpose - that is to say, contributes nothing to a continuation of the sexual process" ([3], p. 211). Freud will again reduce such difference in the 1923 text entitled The Infantile Sexual Organization $^{3}$, in which he states: "we must also suppose that the choice of an object, such as we have shown to be characteristic of the pubertal phase of development, has already frequently or habitually been effected during the years of childhood: that is to say, the whole of the sexual currents have become directed towards a single person in relation to whom they seek to achieve their aims. This then is the closest approximation possible in childhood to the final form taken by sexual life after puberty" ([6], p. 142). Hence, the genital sexuality's primacy and object choice are described as acquired during the infantile phase. What is left for the pubertarian movement?

The second point concerns woman's sexual development, which Freud pays special attention to. This can seem misleading, since it is permanently ingrained in a body's reality and the future of clitoridean sexuality. The latter is the only form of sexuality present during the infantile phase and refers to the phallic logic, undergoing repression. In a second

3 This text was initially supposed to be part of The Three Essays... It seems English resistance led Freud to leave it out of this book. 
moment, "to use a simile - pine shavings can be kindled in order to set a log of harder wood on fire" - in a similar manner clitoridean activity shall transmit the excitation "to the adjacent female sexual parts". Hence, the woman "has adopted a new leading zone for the purposes of her later sexual activity. A man, on the other hand, retains his leading zone unchanged from childhood" ([3], p. 219).

How could Freud propose these arguments whilst staying faithful to the unique libido theory? If indeed the Feminine cannot find support in libido - meaning there is no feminine libido - what support can be given to this "new directive zone" - the vagina - which reveals itself during puberty? How can we fit this into Freud's theorical body? Freud does not give us an answer. It seems we have discovered Freudian theorization's major obstacle. Indeed, it cannot qualify given the epistemological constraints of its time - this beyond-the-phallic dimension suggested by Freud - and highlights, according to us, the intuitive and theoretical power of his contributions. We shall retain that the limit of his research is the beginning of pubertarian transformation, that is, situated prior to a possible theorization of the pubertarian.

Despite the important theoretical contributions they introduce, Freud's works concerning both sexes' sexual development, published after The Three Essays don't bring any elements that contradict these hypotheses.

In 1908, in the article On the Sexual Theories of Children, Freud describes how children ask where babies come from: "Again, the penis certainly has a share, too, in these mysterious happenings; the excitation in it which accompanies all these activities of the child's thoughts bears witness to this. Attached to this excitation are impulsions which the child cannot account for - obscure urges to do something violent, to press in, to knock to pieces, to tear open a hole somewhere. But when the child thus seems to be well on the way to postulating the existence of the vagina and to concluding that an incursion of this kind by his father's penis into his mother is the act by means of which the baby is created in his mother's body - at this juncture his enquiry is broken off in helpless perplexity. For standing in its way is his theory that his mother possesses a penis just as a man does, and the existence of the cavity which receives the penis remains undiscovered by him" ([4], p. 218). Also, in 1917, in On Transformations of Instinct as Exemplified in Anal Erotism we read about the cloacae theory of childbirth: "But the penis has another anal- erotic significance (...). The relationship between the penis and the passage lined with mucous membrane which it fills and excites already has its prototype in the pregenital, anal-sadistic phase. The fecal mass, or as one patient called it, the fecal 'stick', represents as it were the first penis, and the stimulated mucous membrane of the rectum represents that of the vagina" ([5], p. 131). Hence, "an organization analogous to the genital one, in which penis and vagina were represented by the fecal stick and the rectum" [5]. This incidentally constitutes a form of regression of genital sexuality.

Hence, the closest the little boy can get to the integration of the complementary object is the intestines. The vagina remains, to the child, a figure of the impossible.

The inability to conceptualize the existence of the vagina during the subject's infantile phase is also found in the 1923 already cited The Infantile Genital Organization. Freud described how the mother is the last one to be dispossessed of the penis: "It is not till later, when the child takes up the problems of the origin and birth of babies, and when he guesses that only women can give birth to them - it is only then that the mother, too, loses her penis. And, along with this, quite complicated theories are built up to explain the exchange of the penis for a baby. In all this, the female genitals never seem to be discovered" ([6], p. 145). And in The Dissolution of the Oedipus Complex [7] Freud states: "The child may have had only very vague notions as to what constitutes a satisfying erotic intercourse; but certainly the penis must play a part in it, for the sensations in his own organ were evidence of that" ([7], p. 176). Regarding the girl, he states: "she does not understand her lack of a penis as being a sex character" [7].

This enriched analysis of the little girl's development and the importance of the pre-oedipal phase brings nuance to Freud's first achievements, but without addressing the principles we have already presented. If, indeed, Freud isolates the little girl's pre-oedipal phase - referring it to her masculine phase - he does not, however, define, according to the reading we propose, the latency period as belonging to the feminine, but more as pertaining to femininity (understood as a mirrorlike construction, reflecting the masculine one, that is, with a phallic reference). By doing so, Freud, without ever explicitly saying it, presents a triphasic evolution of the little girl. The first one is masculine and corresponds to the pre-oedipal phase ${ }^{4}$. The second one, that of femininity, corresponds to the latency phase and refers to the phallic logic ${ }^{5}$. Finally, the third and final one, that of the Feminine, initiated by puberty, is always related, according to Freud, to the moment when the vagina is discovered as a genitalized organ ${ }^{6}$.

We find the expression of these ideas in the text Female Sexuality (1931), in which Freud asks the following question about the little girl: "How, when and why does she detach herself from her mother? We have long understood that the development of female sexuality is complicated by the fact that the girl has the task of giving up what was originally her leading genital zone the clitoris - in favor of a new zone - the vagina. But it now seems to us that there is a second change of the same sort which is no less characteristic and important for the development of the female: the exchange of her original object - her mother - for her father. The way in which the two tasks are connected with each other is not yet clear to us" ([8], p. 225). We observe how Freud questions the connection between these two phenomena, despite them

4 Same erogenous zone -the clitoris and the penis are equivalent on the libidinal level - and same sexual object, the mother.

5 The little girl keeps her first erogenous zone but changes sexual object, the father replaces the mother.

6 Erogenous zone and sexual object are different according to sex. 
being chronologically separate (the change of object during the oedipal phase, and the erogenous zone during puberty). To us, such anachronism constitutes the link of the little girls' triphasic development theory, never stated as clearly by Freud in this other quote: "We believe we are justified in assuming that for many years the vagina is virtually nonexistent and possibly does not produce sensations until puberty. It is true that recently an increasing number of observers report that vaginal impulses are present even in these early years. In women, therefore, the main genital occurrences of childhood must take place in relation to the clitoris. Their sexual life is regularly divided into two phases, of which the first has a masculine character, while only the second is specifically feminine" ([8], p. 228).

In Femininity [9], Freud states: "We are now obliged to recognize that the little girl is a little man" and that "and that the truly feminine vagina is still undiscovered by both sexes" ([9], p. 118). It is interesting to highlight what Freud, incidentally, introduces here. The Feminine is not a discovery unique to the little girl; the boy is also implicated - which seems to highlight its non-imaginary character, beyond the specular realm, responding to a pubertarian real (in the lacanian sense), specific to puberty and concerning both sexes.

Because of the impossibility to theorize it, the use of the body's real in order to establish what is new during puberty leads Freud to logically insist that: "psychology too is unable to solve the riddle of femininity (...) In conformity with its peculiar nature, psycho-analysis does not try to describe what a woman is - that would be a task it could scarcely perform but sets about enquiring how she comes into being, how a woman develops out of a child with a bisexual disposition". Even the hypothesis of "the elementary influence of the mutual attraction between the sexes is of no help: but we are not going to find things so easy; we scarcely know whether we are to believe seriously in the power of which poets talk so much and with such enthusiasm but which cannot be further dissected analytically" ([9], p. 116).

What shall we retain from this reasoning?

Freud implemented a tight, theoretical tracking system of the differential evolution of boys and girls in their infantile phase. Its principles are: the first phase of the girl is properly masculine; femininity differs from masculine evolution based on the observation that the difference between the sexes is a result of a change of sexual object when the little girl enters the oedipal phase. The advent of the feminine characterizes the pubertarian; it results from an experience (the pubertarian real) shared by the subject of both sexes.

This theoretical contribution reaches an inescapable obstacle, impossible to be theorized at Freud's time - it is the real of the body induced by puberty's somatic transformations, specified by that of the girl's change of erogenous zone.

"It is not until development has reached its completion, Freud highlights, at puberty that the sexual polarity coincides with male and female. Maleness combines subject, activity and possession of the penis; femaleness takes over object and passivity. The vagina is now valued as a place of shelter for the penis; it enters into the heritage of the womb" ([9], p. 145).

\section{Jacques Lacan's Contributions}

Jacques Lacan did not pay any more attention to the pubertarian phase than Freud did ([3], Introduction). We could, however, say that Lacan surpassed it, and attached himself to a theorization of the adult subject's sexuality based on the question of feminine jouissance's specificity. This was possible due to the epistemological evolution and the theoretical contributions accumulated since Freud.

Based on Serge André's book What does a woman want?, we shall try to present this theory's main points. We will see that by default the remaining gap between the two theories (Freud's and Lacan's, that is, between the infantile and the adult subject) - allow for a possible theorization of the pubertarian.

For Jaques Lacan, the woman is not-all determined by the phallus' function. There is a "supplement" for the woman, a beyond-the-phallic dimension that offers a relationship to the real that man, who is entirely conditioned by the phallic function (that is, by the signifier) does not have (except perhaps through fantasy).

This proposal can be articulated to the Freudian position of the woman as not-all subject to the Oedipus complex (namely Freud's proposal regarding the unfinished character of the feminine Oedipus complex [7]). and hence to the law of castration. It constitutes a development, thanks to the displacement operated by Lacan, from the question of the desire to that of jouissance, from the biological reality of sexual differences to the observation of such difference on the language structure.

To defend this point, Lacan flips the Freudian proposal that castration is a barrier to sexual jouissance - by turning castration into the condition for a possible access to sexual jouissance. "It is because of castration that the realm of sexual jouissance opens itself to us" ([1], p. 229).

According to this conception, castration outlines a possible jouissance - a sexual one - from another, not properly sexual, impossible one, which corresponds to that of the primal horde's father.

Such delineation is the result of signifier's effect particularly the phallic one - which, on the one hand forbids jouissance - the jouissance of being - and on the other, makes it possible via the introduction of the sexual dimension in the human being, to become the semblant's jouissance.

The question of the Feminine emerges at the intersection of these two fields, precisely in order to show how they overlap or disconnect.

Indeed, if language grants access to sexual jouissance, it does so in the name of a particularity of its signifying organization, where a signifier lacks, that of the woman's sex. There is only one sexuation signifier - the phallus -, which explains why, on the unconscious level, "there is no sexual relation", there is no formable relationship between the two sexes. Hence, a complementary relationship between sexes 
cannot be envisioned.

The Other's hole signifier, the $S(\mathbb{A})$ echoes this emptiness of the woman's side. The whole question stands on the ambiguity of the Other's status and the feminine status regarding this Other. Thus the Woman is placed on the level of the radical Other, the Other sex, about which the unconscious cannot say anything, except the lack, which is why the feminine has its foundation on this Other jouissance - other than contained by language, the phallic one, the sexual one. We thence propose to write "Feminine" with a capital F, as it has no inscription in the language that structures the unconscious.

It is why "if a woman can embody the form a subject hopes to unite with, it is because the woman, or her body, has the value of a metaphor of the Other with which there is no signifiable relation. Just like the Other, the woman is incomplete, not-all subject to the signifier's law" ([1], p. 251). Man can only make use of the latter and of his body's real within the limits of what the exercise of words can produce, that is, a phallicized object - whilst the woman meets the Other beyond the language dimension, non-existing Other real in the signifier's level, foundation of the sexed Other's place.

The disjunction between body (Real) and sex (Symbolic) also situates the woman at the object a's place, in reference to man, that is, a rest from the body's real only perceptible through fantasy. And the end, to ma, is woman's only consistency, as a partial object of what could be the Other's body (sight, voice, skin, more or less fetishized body parts).

Hence, once the sexual act's goal is to meet the real Other the sexual act's final intent is to get jouissance from the Other, from the Other's body - so called sexual jouissance becomes an obstacle. Because it is determined by phallic jouissance, it constitutes a defense against the Other's jouissance or its body, since the phallus, as a signifier, interposes itself between the Other's body and the subject's, like a screen covering our wish to obtain jouissance from the Other's body.

Such is the law of castration which makes the sexual act an eternal failure, where we can endlessly verify the absence of sexual relationship, and the failure to unify the subject and the Other as a body. Lacan names the resulting jouissance, on the masculine end, "the idiot's jouissance", meaning this jouissance does not need the Other. Given the impossible nature of the Other's body jouissance, the sexual act remains fundamentally connoted as unsatisfactory and referred to this "Encore" Lacan used to name his Seminar [14] and where he particularly develops such theoretical aspects.

Why would man suppose the existence of another jouissance, about which he is entirely inept to perceive anything?

On the imaginary level, the enigma a woman represents is enough to lead him to suppose a jouissance different from his, to which only she has access.

On the real level, phallic jouissance leads to a partial, outof-body jouissance (since it is referred to the signifier), that contains in itself the hypothesis of an Other jouissance, namely the Other's body jouissance - one that remains beyond the limits of the sexual act and that remits to a real.
That particular jouissance we can only experience "mentally", as Lacan says [16]. The effect of the pubertarian real results, as we propose, from puberty's physiological transformations.

Finally, on the symbolic level, is it above all to the signifier's effect - namely the phallic one - that we should report the belief of a beyond of the signifier itself, due to the cutting effect it operates on the field of the real. "Language does not keep its promises: it makes us believe in the Other at the same time as it removes it from us: it evokes a faraway bodily jouissance while at the same time making it inaccessible" ([1], p. 249), says Serge André.

What answer does the woman give to the question posed by man of a jouissance Other than the one named by the signifier? What does she experience?

The pervert tries to answer by saying we can believe the Other and the subjectivation of the Other's jouissance. The woman, however, does not need to believe this, since she is situated at the very place where the question of the Other's existence is posed; hence she has no need to answer it. Indeed, the pervert aims this out-of-subject, the feminine, without ever being able to attaint it. The woman makes the reverse path; she tries to escape thus non-phallic dimension, this additional dimension, and to subjectify it. The woman does not cease to testify "the impossible subjectivation of the body as Other", says Serge André. She does not cease to signify that the jouissance she can experience remains foreign to her, impossible to subjectify since, as a subject, she cannot only restitute her relation to the signifier, the phallus, and not the body as such.

The woman's position and her radical difference from man, whenever she experiences this "foreign" jouissance, can be understood through her relation to the de-subjectivation that overwhelms her. She is then ready to do anything in order to save her position as a subject and hence make sure there is no Other's Other, as Lacan pointed out (that is, a subjectivation project of this Other jouissance): "to the point where there is no limit to the concessions made by any woman for a man: of her body, her soul, her possessions" ([14], p. 40).

Thence, the woman renounces Man, with a capital M, and does everything - support masculine fantasy, embrace phallic domination, play a masquerade, play the inexistent Other... in order to protect her subjective position through the acceptation of man's castration. She chooses sexual jouissance - which signs the failure of the Other's body jouissance - because she knows that by introducing a harsh disjunction between body and subject, the latter's place is nevertheless preserved "Finally, we expect a woman to confirm that there is no sexual relation, except through the semblant, because she knows that if men weren't castrated and women not divided, if sexual relation could happen, it would lead to a subjective catastrophe" ([1], p. 255).

Such is the beginning of any love demand. We shall place it in the breach we have already observed between signifier's jouissance (phallic, man's) and the sexuated Other's jouissance (The Woman). Love seeks to orchestrate an encounter which, on the jouissance level, is impossible. It tries to remediate the fact that there is no sexual relation from 
the unconscious' point of view, by contesting this very principle. It bases itself on a possible, successful encounter that would sign the failure of the unconscious desire, always articulated to a missed encounter.

It is important to highlight that if love tries to fix the defaulting sexual relation, it does so in a non-sexual dimension: "when we love, it is not about sex", Lacan states. Love is fundamentally a-sexual.

This is how we can understand that love is part of the language structure, that is, the basis of law; hence it cannot object castration and the feminine not-all. Indeed, on the symbolic level, what is at stake regarding love is based on the encounter between two subjects. In the failing of the Other's being, something appears that is neither a thing nor a being, but a subject. Thus, love works as a suppléance, by changing the terms of the relation, given the impossible conjunction between the subject and the body, that we can verify through jouissance. It establishes a subject-to-subject relation, where the copula is the knowledge one supposes from the each other" ([1], p. 267).

It is a fundamental position for whoever occupies the feminine end: will the part that escapes the signifier's register, that of the sexuated Other, find itself thus subjectified? The woman's love demand can be attributed to this: to the search for this missing unconscious supplement, susceptible to making her a subject where she precisely isn't. This search subjectifies a part of herself that cannot be subjectified, and that her body represents (in Freudian terms we can refer this to the famous "female penis envy"). Hence, the awaited words the woman asks from her partner during foreplay, before the sexual act. She calls him to entertain the body's jouissance on the level of sexual jouissance, that of the signifier, which could make her a whole-subject. Such is the consequence of this subjective defection that marks her as a woman. If women want to be loved, it is because they want to be made subjects precisely at a level where the signifier abandons them.

"What does a woman want", really? That something appears at the place of this hole in the Other, of this lacking signifier where she disappears as a subject. But to what instance does feminine jouissance refer to? To the real one, a real that escapes all possible imagination and symbolization. This hole can be supposed as real and observed as such inasmuch as it corresponds to the existence, in the Other, as the space of a word, a signifier, $S(\mathbb{A})$. This Other is the radical Other - since there is no Other's Other -, that is, the sexuated Other and that defines the woman's place ${ }^{7}$.

\section{A Pubertarian Theory}

Between Freud's theoretical culmination - that we have already situated at the limits of the infantile - and Lacan's concerning adult sexuality - could we find space for a possible theorization of the pubertarian, which, according to us, is articulated with the advent of the Feminine? How do we identify it?

7 Cf. Jacques Lacan's sexuation tables.
Philippe Gutton' s contributions will be valuable to us.

In his works - namely Le Pubertaire - Gutton radicalizes the adolescence's theoretical approach so far elaborated, where the main principle of the pubertarian was the novelty of puberty's physical transformations. Thus, he reintroduces the drive dimension in the theorization of adolescence leading to a metapsychological specificity of the pubertarian. The concept of sexual complementarity signifies what is at stake, on the psychic level, concerning puberty's bodily transformations: "puberty is to the body what the pubertarian is to the psyché" ([12], p. 193).

To do so, Gutton aligns himself with Piera Aulagnier's theory of the "organ's adequation based on the model of the couple erogenous zone/partial object" ([12], p. 197) founded on the observation of the infans ${ }^{8}$ mouth/breast pair. Her originality lies on the extension of this "origining" thesis regarding the infans to adolescence. Indeed, the bodily novelty induced by puberty's transformations is, according to this perspective, described as the source of a new "experience", of a "pubertarian archaic" that includes, in its principle, its adequate object ${ }^{9}$ (the breast model for the infans' mouth), prior to any possible figuration or representation.

This is the argument that authorizes us to speak of a pubertarian real, in the lacanian sense ${ }^{10}$, that is, as a new experience induced by puberty's bodily transformations. It initiates a new sensoriality - far from any figuration or representation - to which an adequate object, called "complementary", corresponds. We insist on the nonfigurative character of this adequate object, meaning such complementarity is prior to any imaginary dimension - so often solicited in theorizations of adolescence. This complementarity is neither experienced on the fantasy level nor in reality, (which would grant the newly emerged genitality the means of finding the so much idealized dyad mother/infans) but constitutes an experience that mobilizes a "drive knowledge" ", a notion already present in Freud's works: "with this, however, the child also experiences the first occasion for a 'psychical conflict', in that views for which he feels an instinctual kind of preference, but which are not 'right' in the eyes of the grown-ups, come into opposition with other views, which are supported by the authority of the grown-ups without being acceptable to him himself (...) These false sexual theories, which I shall now discuss, all have one very curious characteristic (...) What is correct and hits the mark in such theories is to be explained by their origin from the components of the sexual instinct which are already stirring in the childish organism. For it is not owing to any arbitrary mental act or to chance

\footnotetext{
8 Infans designates the period during which the child has no access to language. 9 "the masculine organ is felt in the presence of the feminine organ, present or hallucinated, and inversely" ([12], p. 197).

10 The real is opposed to the imaginary and the symbolic (RSI), whilst composing with them a triad that Lacan formalized through the Borromean knots. Reality (which is not the real) is composed by the articulation of these three registers and their disjunction can call for a suppléance (a fourth knot susceptible of suturing them) or lead to a complete dissolution (psychotic decompensation).
} 
impressions that those notions arise, but to the necessities of the child's psychosexual constitution; and this is why we can speak of sexual theories in children as being typical, and why we find the same mistaken beliefs in every child whose sexual life is accessible to us" ([4], p. 214-215).

Philippe Gutton's work does not stop here, in his theorization. After the first phase of the pubertarian establishment of a new origination dimension, of a pubertarian real opening to "sexual complementation" Phillipe Gutton will theorize what becomes of this new experience, through its resonance with Oedipus (pubertarian Oedipus) and how it figures in the puberty scenes, giving access to the processes mobilized at a second time, which he named Adolescens ${ }^{11}$ : "The emerged pubertarian should be considered in regards to its anchoring in the biological real, exerting a pressure on the three instances and confronting the incest barrier inherited from the infantile Oedipus. The adolescens, elaborative concomitant or delayed work (we do not see two stages), is only feasible based on pubertarian material. It uses the idealization procedures matured during childhood, especially the ego ideal and identification. Its goal is a desexualization of incestuos representations leading to the potentially adequate choice of object" ([12], p. 11).

Our thesis [17] is that, at this first pubertarian phase, something we qualify as "Feminine" starts to appear. The pubertarian real is nothing but the vagina, whose discovery Freud situates as late as puberty. To Lacan it is a relation to a real that specifies feminine jouissance. The pubertarian real is hence this newly genitalized organ, experienced only at adolescence by both sexes, and escaping any possible figuration or imagination - thus symbolization. According to Lacan "there isn't, properly speaking, a symbolization of the female sex as such (...) And this because the imaginary only supplies an absence, whilst elsewhere there is a prevalent symbol" ([13], p. 174). We place ourselves in the continuity of these two author's theoretical contributions.

Our proposal, which situates the advent of the Feminine as a pubertarian specificity for both sexes' subjects, opens the possibility of other considerations we find valuable. Indeed, at the place of quantitative sexuality differential (having or not having) of the infantile, a qualitative one appears with puberty, that, given the newly integrated relation to the real, found, to us, the Other sex dimension, with capital $\mathrm{O}$, that is, radical alterity. We seem to rediscover here Freud's theory about auto-erotic infantile sexuality (partial drives) as well as the post-pubertarian one (altruistic sexual drive [3]), leading to the discovery of the adequate object: the Other sex's other, inasmuch as it represents a real alterity, one that integrates a beyond of body parts that sustain partial drives. Situating this Other sex's other - the adequate object according to Freudian terminology - at the level of sexual drives seem to ensure a basis that is different from an imaginary one, granting it a support and a metapsychological consistency allowing for an analytical theorization of the pubertarian.

The whole work of adolescence consists in the masking of

11 A neologism that phonetically, in French, combines "adolescent" and "sense" this alterity, of a real that escapes all imaginary dimension and that fundamentally questions the system elaborated during the infantile period. The Other sex's other can be the "adequate" object, as long as it integrates this part of real belonging to anatomical sexual difference and this part of consistency that operates as a veil covering the psychically unbearable pubertarian real. All avatars are equally possible, including the whole of adolescence's psychopathology and the realm of substitutive objects, such as the addictive ones, for instance drug abuse or mental anorexia.

\section{Conclusion}

It is always interesting to observe how history is shaped by intellectual discovery. Given that the adolescent experience is at stake, is this not a tautology, coming from a text that explores adolescence? From being virtually non-existent until the French Revolution, both adolescence and puberty have slowly and progressively become epistemological objects, only recently subject to analytic theory [18].

As time passes, it seems to us that we have reached a moment where the theoretical means available allow us to progress in the field of the pubertarian novelty. The contribution of Lacan's notion of real [15] seem crucial to this matter, as it is the only one capable of inscribing the radicalism that separates the semiology and the nosology of these two phases that compose man's evolution, that is, the theoretical tracing of what differentiates the infantile and the juvenile.

We believe our proposal - the advent of the Feminine as a pubertarian novelty - answers this demand. By joining what already loomed in Freud's works and what we find in Lacan's teachings, our proposal imposes this Other sex and its jouissance's singularity as true alterity - true in regard to the phallic one on the one hand and consequently, the infantile one on the other.

\section{References}

[1] André, S. (1999). What does a woman want? New York: Other Press.

[2] Freud, S. (1901-1905). A Case of Hysteria, Three Essays on Sexuality and Other Works. The Standard Edition of the Complete Psychological Works of Sigmund Freud, Volume VII.

[3] Freud, S. (1905). Three Essays on the Theory of Sexuality.

[4] Freud, S. (1908). On the Sexual Theories of Children. The Standard Edition of the Complete Psychological Works of Sigmund Freud, Volume IX (1906-1908): Jensen's 'Gradiva' and Other Works, 205-226.

[5] Freud, S. (1917). On Transformations of Instinct as Exemplified in Anal Erotism. The Standard Edition of the Complete Psychological Works of Sigmund Freud, Volume XVII (1917-1919): An Infantile Neurosis and Other Works, $125-134$.

[6] Freud, S. (1923). The Infantile Sexual Organization. 
[7] Freud, S. (1924). The Dissolution of the Oedipus Complex. The Standard Edition of the Complete Psychological Works of Sigmund Freud, Volume XIX (1923-1925): The Ego and the Id and Other Works, 171-180.

[8] Freud, S. (1931). Female Sexuality. The Standard Edition of the Complete Psychological Works of Sigmund Freud, Volume XXI (1927- 1931): The Future of an Illusion, Civilization and its Discontents, and Other Works, 221-244.

[9] Freud, S. (1933). New Introductory Lectures on PsychoAnalysis. The Standard Edition of the Complete Psychological Works of Sigmund Freud, Volume XXII (1932-1936): New Introductory Lectures on Psycho-Analysis and Other Works, 1-182.

[10] Freud, S. (1977). La vie sexuelle. Paris: PUF.

[11] Hoffmann, C., Lauru, D. \& Pickman, C-N. (1999). Problématiques adolescentes et direction de la cure. Toulouse: Eres.
[12] Gutton, P. (2013). Le Pubertaire. Paris: PUF.

[13] Lacan, J. (1997). The Seminar of Jacques Lacan Book III The Psychosis (1955-1956). New York: W. W. Norton \& Company.

[14] Lacan, J. (1998) The Seminar of Jacques Lacan Book XXEncore (1972-1973). New York: W. W. Norton \& Company.

[15] Lacan J., La Troisieme: English Translation Yolande Szczech, King's College London, August 2016 https://www.researchgate.net/publication/307210365.

[16] Lacan, J. (2018). The Seminar of Jacques Lacan Book XIX -... Or Worse (1971-1972). Cambridge: Polity Books.

[17] Ouvry, O. «Le concept de "Complémentarité des sexes", intérêt pour une spécificité métapsychologique de l'Adolescence», 1998. Doctorate thesis, University of Paris 7 (non published).

[18] Perret-Catipovic M., Ladame F. (1997). Adolescence et psychanalyse: une histoire. Paris: Delachaux et Niestlé. 